\title{
The Immune-Pineal Axis: the Role of Pineal and Extra-Pineal Melatonin in Modulating Inflammation
}

\author{
Regina P. Markus* and Zulma S. Ferreira \\ Laboratory of Chronopharmacology, Institute of Bioscience, Universidade de São Paulo, São Paulo, Brazil
}

\begin{abstract}
Participation of the pineal gland and melatonin in the innate immune response is part of a dynamic and intricate network that acts throughout the inflammatory response, integrating signaling pathways and regulatory processes at the molecular, cellular and organism levels. The pineal gland is a target for pathogen-associated molecular patterns and for inflammatory mediators, and melatonin, which may be produced by the pineal gland or by activated immune-competent cells, plays a role in modulating inflammatory responses. Nocturnal melatonin surge is suppressed at the beginning of an inflammatory response in order to allow a full mounting of an innate immune response at any hour of the day. Melatonin produced at the site of a lesion by activated immune-competent cells favors phagocytosis and reduces inflammatory reactions that could promote tissue lesion. Here, we discuss the mechanism underneath this crosstalk between the pineal gland and the innate immune response and extend the concept of an Immune-Pineal Axis.
\end{abstract}

Keywords: Melatonin, pineal gland, immune-pineal axis, cytokines, LPS, corticosteroid, nuclear factor kappa B

\section{INTRODUCTION}

Organisms are continuously in contact with aggressors, which need to be sensed and destroyed. The innate immune system recruits leukocytes to infected sites in order to identify and remove bacteria, cell debris and macromolecules. The inflammatory response also comprises a recovery phase responsible for the healing of the tissue. The four cardinal signals of the inflammatory response described by Celsus (30 BCE - 38 AD) include redness, heat, swelling and pain. Later, Galen (Claudius Galenus, AD 129 - 199/217) proposed that if there is not a proper resolution of the acute inflammation, a fifth signal appears: the lost of function.

\footnotetext{
*Correspondence to: Regina P Markus, Laboratório de Cronofarmacologia, Instituto de Biociências, Universidade de São Paulo, Rua do Matão - travessa 14 sala 323, 05508-900 São Paulo, Brazil. Tel.: +55 11 30917612; Fax: +55 11 30649279; E-mail: rpmarkus@usp.br..
}

The initial steps of the inflammatory response are the release of mediators by resident cells and the migration and activation of neutrophils, which release factors that summon other leukocytes and generate reactive oxygen and nitrogen species. These reactive species kill bacteria and any other nearby cells. The efficiency of the inflammatory response relies on a proper migration of cells to the site of the lesion. Spurious migration and activation of cells leads to a disruption of the healthy tissue.

Many authors have proposed an anti-inflammatory role for exogenous melatonin [for review see 1, 2]; however, these effects were obtained with very high concentrations, some 100 to 1000 times higher than those found in nocturnal plasma. Therefore, they were not attributed to a nocturnal melatonin surge.

Studies evaluating the adaption of the immune response elegantly suggested that melatonin secreted by the pineal gland plays a role in regulating the innate and acquired immune responses [3-5]. The redirection of energy consumption from reproduction to survival in 
the winter was due to the increase in the duration of the nocturnal melatonin peak [6]. In summary, two lines of research attributed a role in the immune response to melatonin: one focusing on the so-called pharmacological effect, and the other on the increase in the duration of nocturnal pineal synthesis.

In this review, we will describe experimental data, which suggest that the hormone of darkness, melatonin, impairs neutrophil migration in healthy subjects, providing conditions for maintaining circulating leukocytes in the blood stream. In addition, pineal melatonin synthesis is suppressed by pathogen-associated molecular patterns (PAMPs) and pro-inflammatory cytokines, creating the conditions for a proper mounting of an inflammatory response, independently of the hour of the day. As the inflammatory response progresses to the healing phase, melatonin produced by activated immunecompetent cells plays the role of an antioxidant and anti-inflammatory molecule. Melatonin synthesized at the site of the lesion has no relationship to photoperiodic information, and it is worthwhile to remember that the primitive biological role played by this indolamine was that of an antioxidant molecule [1]. In order to close the cycle that defines an immune-pineal axis, inflammatory mediators contribute to restoring pineal gland activity. We summarize this cycle in Fig. 1, which shows our working hypothesis during the last ten years. In this review, we will revisit the experiments that allow for the proof of this working hypothesis.

\section{VASCULAR PERMEABILITY - A PROCESS REGULATED BY THE PINEAL GLAND HORMONE}

At the end of 1990, an undergraduate student, looking to model biological data, measured the difference in the size of the paws of mice injected or not with BCG (bacillus Calmette-Guerin) for 90 days at the light and the dark phase of the day. The modeling of the chronic phase ("plateau") of the inflammatory response was adjusted to a senoidal curve with a period of $24 \mathrm{~h}$ [7]. The paw was thicker during the day and thinner at night (Fig. 2).

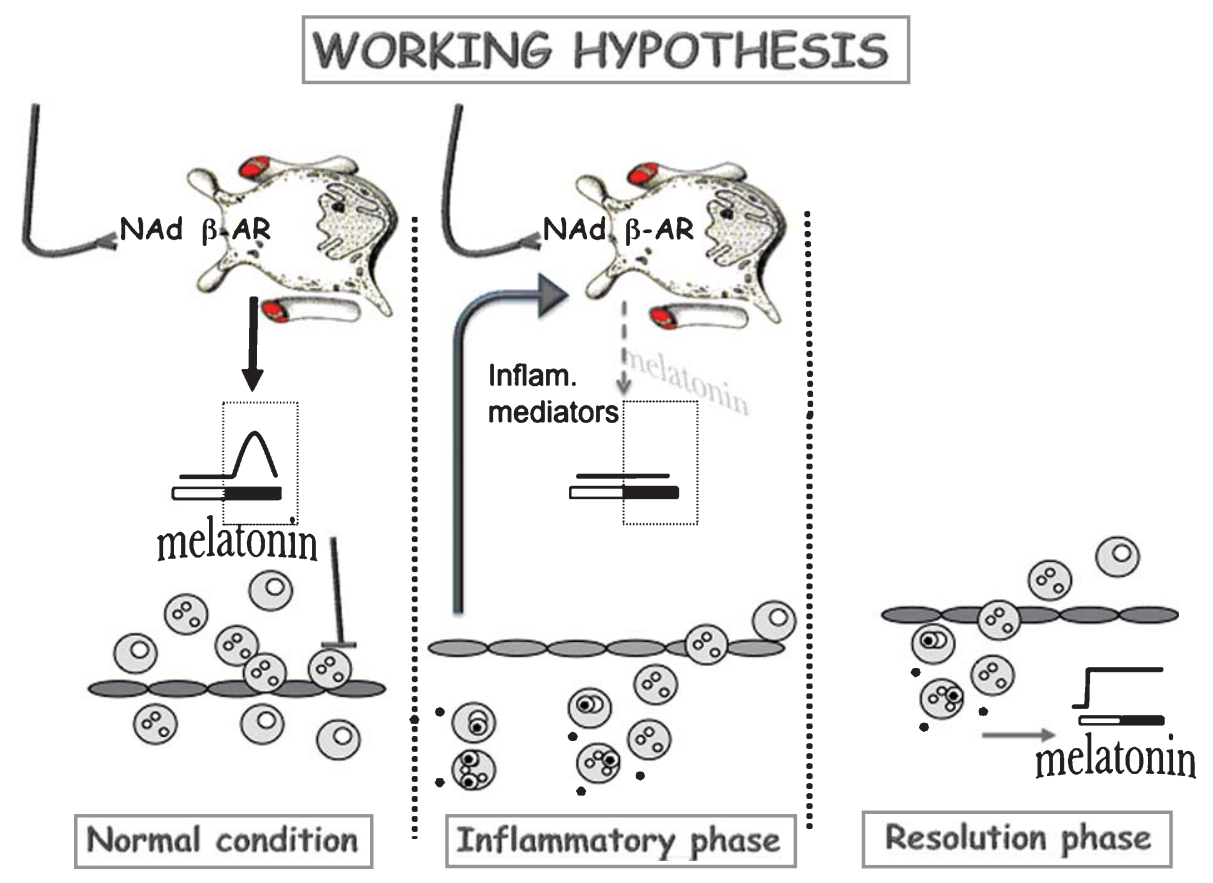

Fig. 1. The Immune-Pineal Axis working hypothesis - In normal conditions (left panel) the activation of $\beta$-adrenoceptors by noradrenaline released from sympathetic neurons induces the synthesis of melatonin, which is promptly released in the blood and liquor. Melatonin impairs the migration of leukocytes from the blood stream, avoiding unwanted triggering of inflammatory responses. At the inflammatory phase (central panel) the early mediators of inflammation, such as the cytokine TNF, blocks pineal melatonin synthesis induced by noradrenaline, impairing the nocturnal melatonin surge and favoring the migration of cells to the site of lesion. When the inflammatory response enters the recovery phase (right panel) the activated leukocytes that migrate to the site of lesion produces melatonin, which attains very high concentrations and together with other anti-inflammatory mediators contributes for the ending of the inflammatory response. 


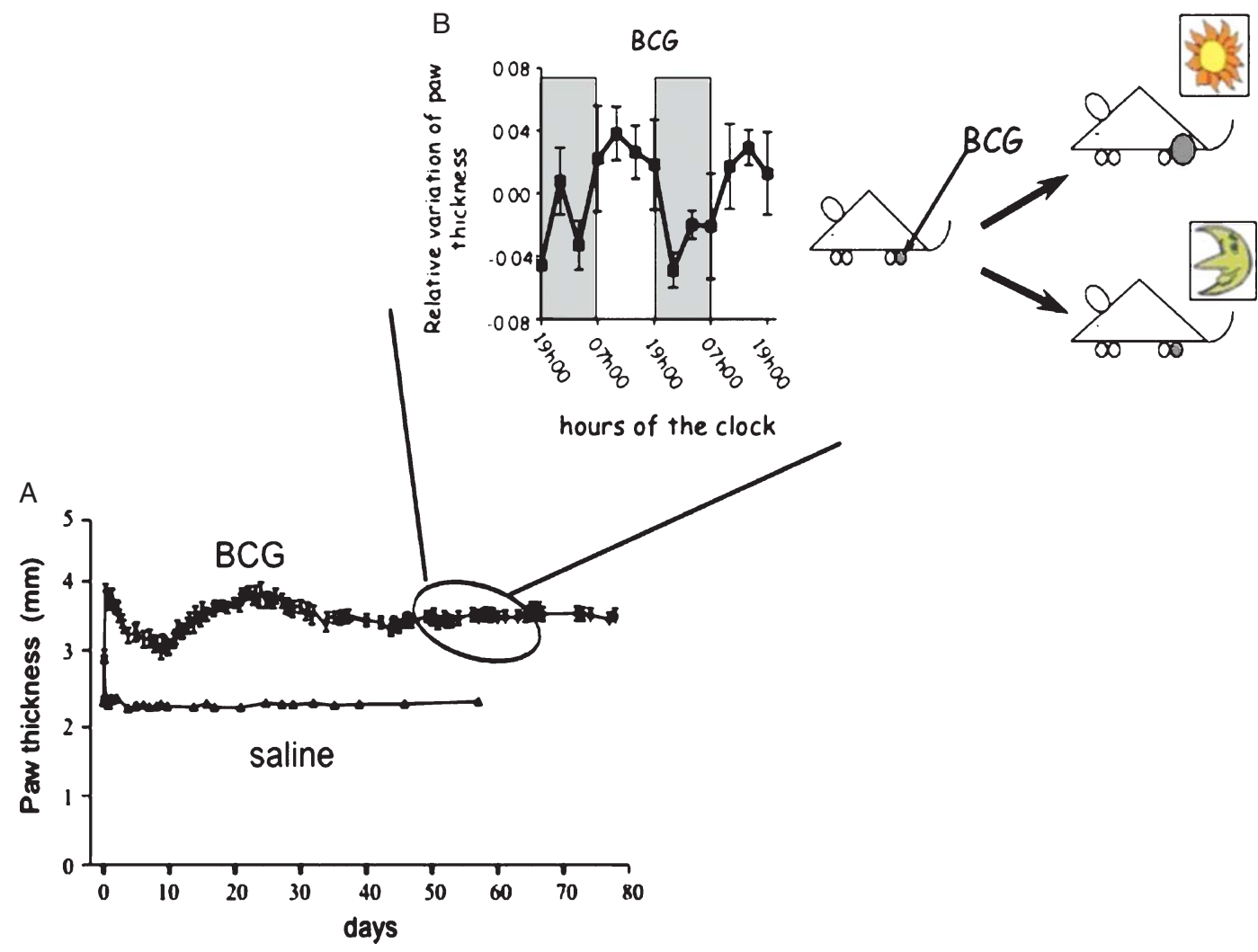

Fig. 2. Daily rhythm of inflamed mice paw. A - Daily size $(\mathrm{mm})$ of the paw of mice injected with BCG $(n=19)$ or saline $(n=10)$ at day zero. The measures obtained at daytime and nightime for 80 days shows the time-course of a chronic inflammatory response. An immediate increase in paw-size at day zero and a second slow increase at day 30, followed by an stable plateau. The mathematical modeling of the plateau disclosed a senoidal rhythm with a period of $24 \mathrm{~h}$. B - The $24 \mathrm{~h}$ variation in paw size was confirmed by measurements obtained at regular $4 \mathrm{~h}$ intervals 30 days after BCG inoculation. The acrophase was between $09 \mathrm{~h} 00$ and $13 \mathrm{~h} 00$ and the nadir between $21 \mathrm{~h} 00$ and $01 \mathrm{~h} 00$. As shown in the graphics, lights were turned on and off at $07 \mathrm{~h} 00$ and $19 \mathrm{~h} 00$, respectively. Data are expressed as mean \pm standard deviation of the relative variation of mean paw thickness along the record period for each mouse. Reprinted from [7] with permission of "John Wiley and Sons".

Dark-mediated activation of glutamatergic pathways from the suprachiasmatic ( $\mathrm{SCN})$ to the paraventricular nucleus (PVN) of the hypothalamus activates the sympathetic input of the pineal gland, which is innervated by the conarii nerves that originate in the superior cervical ganglia (for a review, see [8]). The sympathetic terminals release noradrenaline and ATP, which act on $\alpha 1$ and $\beta 1$ adrenoceptors and P2Y1 purine receptors $[9,10]$. The activation of $\beta$ adrenoceptors is essential for the translation of the gene and/or activation of the key enzyme in melatonin synthesis (alkyl-arylamine-N-acetyltransferase, AANAT), which converts serotonin to $\mathrm{N}$-acetylserotonin (NAS), the precursor of melatonin. The enzyme hidroxy-indole-O-methyltransferase (HIOMT) converts NAS to melatonin.

The suppression of the nocturnal melatonin surge by removing the pineal gland or the superior cervi- cal ganglia for more than 30 days abolished the daily variation in paw size [7]. The nocturnal administration of melatonin restored the rhythm of the lesion. The same variation profile was observed when we measured the changes in vascular permeability; the mechanism underlying changes in paw size (Fig. 3).

Serum levels of glucocorticoids are consistently and markedly increased during chronic inflammation [11], and adrenalectomy increases vascular permeability in inflamed areas [12]. Therefore, both hormones, melatonin and corticosterone, could be responsible for the daily variation in vascular permeability. As a matter of fact, pinealealectomy and adrenalectomy abolished the nocturnal reduction in vascular permeability induced by BCG; however, melatonin was able to restore the rhythm in both experimental conditions (Fig. 3). In addition, the nocturnal rise in the excretion of the main melatonin metabolite 


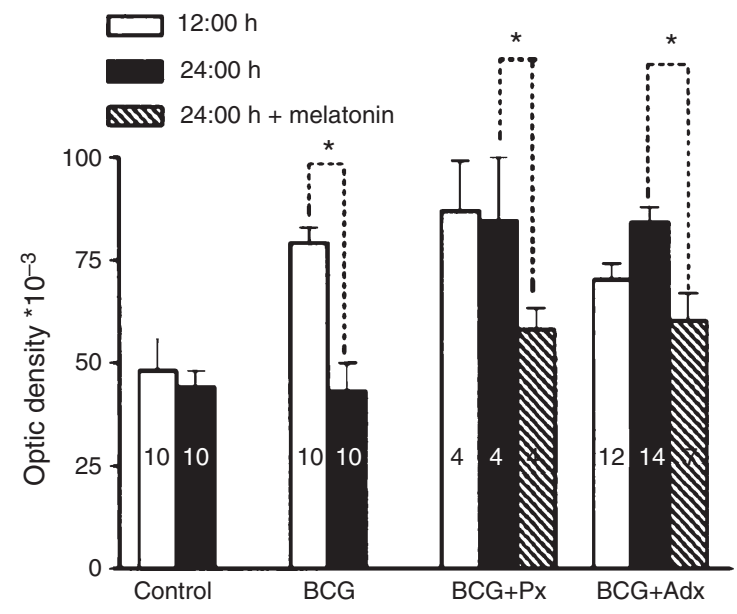

Fig. 3. The variation of the vascular permeability in mice paw at daytime and nighttime 45 days after inoculation of BCG. The vascular permeability was evaluated at midday and midnight by the method of Evans-blue-albumin outflow. No difference between day and nighttime was observed in the paws injected with saline. The higher vascular permeability observed at daytime in BCG inoculated mice was abolished by pinealectomy (Px) or adrenalectomy (Adx). Nocturnal administration of melatonin reversed the effect of both pinealectomy and adrenalectomy. Numbers inside the bars show the number of mice in each experiment. Dotted lines indicate the two compared groups. * - groups are significantly different at $p<0.05$. Results are expressed as mean \pm standard deviation. Reprinted from [39] with permission of "John Wiley and Sons".

in the urine, 6-sulfatoximelatonin, was abolished in adrenalectomized chronic inflamed mice. This surprising result strongly suggested that the pineal gland is a target for corticosterone.

\section{ENDOTHELIAL LAYER REACTION TO ENDOCRINE AND PARACRINE MELATONIN}

Cell migration from blood to tissue implies the crossing of the endothelial barrier. Endothelial cells form a unicellular layer that is in direct contact with the blood stream. These cells play a role in controlling either the vascular tone or the migration of cells from blood to tissue.

Melatonin concentration at the pM-nM range, which is found in nocturnal plasma, reduces the rolling and adhesion of leukocytes to endothelial cells [13]. The pharmacological profile of melatonin analogs suggests that the control of rolling and adhesion is mediated by MT2 and MT3 melatonin receptors, respectively. Both responses are blocked by the competitive antagonist luzindole. The partial agonist of the MT2 melatonin receptor, 4-PPDOT, mimics the inhibition of rolling, while the agonist for the MT3 receptor, MCA-NAT, inhibits leukocyte adhesion to endothelial cells.

The adhesion of neutrophils to endothelial cells is mediated by the interaction of neutrophils with $\beta 2$ integrins (CD18), with adhesion molecules of the immunoglobulin superfamily expressed in endothelial cells [14]. Melatonin did not reduce the expression of CD18 induced by leukotriene B4 (LTB4) or formylmethionyl-leucyl-phenylalanine (fMLP) [15], or the neutrophil-endothelial interaction due to fMLP [13] (Lotufo et al., 2001). Melatonin reduces the interaction induced by LTB4. Since the effect of fMLP is mediated by neutrophil activation, while LTB4 activates both endothelial cells and neutrophils, it was concluded that melatonin at low concentrations acts on endothelial cells.

Melatonin regulates endothelial cell line proliferation and protects both endothelial cells lineages and primary cultures against oxidative stress, DNA damage and death $[16,17]$. Studying the effect of melatonin in primary cultures in rat endothelial cells, we observed that melatonin also inhibits the neutrophil-leukocyte interaction induced by lipopolysaccharide (LPS), a PAMP found in the membrane of gram-negative bacteria [18]. In addition, the nitric oxide (NO)-mediated relaxation of the rat aorta, induced by LPS, was also inhibited by melatonin. In this context, the melatonin effect was due to the inhibition of the nuclear factor kappa B (NFKB) pathway and was not blocked by luzindole. The concentration of melatonin required for the inhibition of the LPS effect is in the nM-mM range and was initially thought to be a pharmacological effect. However, it is now well known that activated neutrophils and macrophages produce melatonin, at the site of the lesion $[19,20]$.

An interesting output of this line of research was that melatonin primes endothelial cells for reducing the expression of the inducible nitric oxide synthase (iNOS) and adhesion molecules, such as PECAM-1 and ICAM-1 [21]. In other words, the expression of these molecules in primary cultured endothelial cells was inversely correlated with the level of melatonin in the blood of the donor animals [21]. In addition, a significant increase in the adhesiveness of endothelial cells obtained from donors with lower melatonin plasma concentration is observed. Considering the increasing interest in applying cell therapy, obtaining grafts with endothelial cells in the quiescent state will certainly favor more homogenous responses.

In summary, both endocrine and paracrine melatonin reduces the reactivity of endothelial cells, impairing their adhesiveness to leukocytes. In the first 
case, the effect is mediated by the activation of melatonin membrane receptors, while in the second case, melatonin inhibits the PAMPs-activated NFKB pathway. The endocrine origin of melatonin is the pineal gland, while in inflamed tissues, activated immune-competent cells are the paracrine source of melatonin.

\section{THE PINEAL GLAND AS A TARGET OF INFLAMMATORY MEDIATORS}

The pineal gland has evolved from the roof of the forebrain (for a review, see 22), in the main part of the epithalamus, and is formed by three types of cells: pinealocytes, glia cells and neurons. In non-mammal vertebrates, the pinealocytes are photoreceptors, and react directly to light, while in mammals, they are not directly sensitive to light. The pinealocytes are the cells responsible for synthesizing the main pineal hormone, melatonin, also known as the hormone of darkness.

Astrocytes and microglia present in the pineal gland have a specific distribution. Astrocytes are located at the proximal end of the gland and along the entire stalk [23, 24]. On the other hand, microglia are part of the parenchyma [25]. Both astrocytes and microglia react to PAMPs derived from gram-positive (LPS) and gram-negative (LTA - lipotheic acid) bacteria [26]. Microglia was suggested to mediate neuroendocrineimmune interactions of the pineal gland [27]. Both microglia and astrocytes expresses IL-1 $\beta$, however, there is an intriguing difference between in vivo and ex vivo cellular expression of this cytokine. In vivo the expression is higher in astrocytes, while in vitro (organ or cell culture) the microglia expression increases. In addition, the metabolism of serotonin in cultured pineal glands is directly affected by intereferon-gamma (IFN$\gamma)$, IL- $1 \beta$, TNF and transforming growth factor- $\beta 1$ [29]. All these cytokines interfere on the metabolism of serotonin [29], however, its translation to melatonin output requires a direct evidence. Cytokines signalize through and modulate the level of activation of several transcription factors, therefore, their final effect on melatonin output cannot be extrapolated from the understanding of serotonin profile. An early paper that deals with the effect of INF- $\gamma$ on melatonin synthesis showed a very complex effect [30]. IFN- $\gamma$ potentiates cultured rat pineal gland production of melatonin induced by $10 \mathrm{nM}$ or $1 \mathrm{mM}$ isoproterenol, while blocks the effect of $100 \mathrm{nM}$ of the $\beta$-adrenergic agonist [30]. Therefore, there are many evidences showing that not only melatonin interact with immune competent cells, but also the pineal gland is able to react to molecules that signalize innate and acquired immune reactions.

The concept of a bidirectional communication between pineal gland and the endocrine system was initially proposed in birds [31]. More recently, we extended the idea and disclosed the mechanisms underlying the effect of PAMPs and cytokines on the mammal pineal gland [32].

The main transduction pathway that signals PAMPs is the NFKB transduction pathway, which occurs in phylogenetically distinct species from insects to mammals [33-35]. This transduction pathway is triggered by membrane receptors of the toll-like receptor (TLR) family that are able to distinguish between different kinds of PAMPs and by activated receptors for pro-inflammatory cytokines. This pathway is turned off by corticosterone, a well-known anti-inflammatory mediator [36]. Despite its well-characterized function in the immune system, NFKB also plays a role in the normal central nervous system [37], including the suprachiasmatic nuclei [38], and in pineal physiology [39].

The NFKB family is highly conserved across species. In mammals, it is composed of five proteins characterized by the REL homology domain (RHD), which contains the crucial functional regions for DNA binding, dimerization, nuclear localization, and interaction with the inhibitory kappa B proteins. The RelA (also known as p65), RelB and c-REL isoforms, but not the p50 and p52 isoforms, have a transactivating domain (TAD) in the C-terminal portion, which is responsible for inducing gene transcription. Upon stimulation, the inhibitory kappa B protein is phosphorylated, ubiquitinated, and degraded by proteasome, releasing the NFKB dimer. The presentation of the nuclear signal localization favors the translocation of the dimer, which binds to specific DNA elements (kappa B motifs) in the promoter region of target genes. Dimers that lack TAD, such as p50/p50, are predicted to block gene transcription (see the reviews $[40,41])$.

The pineal gland rhythmically expresses p50/p50 homodimers during the day [39]. A continuous increase in nuclear NFKB from dawn to dusk is abruptly reduced just after lights are turned off (Fig. 4). Melatonin blocks the nuclear translocation of NFKB in cultured pineal glands and pinealocytes. Although we do not know the role of this pathway in pineal physiology, this is a pivotal pathway for the immune-pineal axis. 


\section{Pro-inflammatory mediators}

The mammalian pineal gland acts as a sensor for injury, as TNF blocks noradrenaline-induced melatonin synthesis in cultured rat pineal glands [42]. Activation of the NFKB pathway transiently blocks Aa-nat translation and the melatonin precursor $\mathrm{N}$-acetylserotonin synthesis. The transiency of the inhibition of Aa-nat translation was blocked by cycloheximide, strongly suggesting that TNF signalizes the synthesis of some protein(s) that reverse the blockage of melatonin synthesis [42].

The pineal gland also reacts to bacterial PAMPs, such as LPS and LTA [26], and we recently showed that it expresses membrane receptors for LPS, such as TLR4 and CD14, which are known to signal thorough the NFKB pathway [43, 44]. These receptors are expressed in the three types of cells, astrocytes, microglia and pinealocytes (data not published). The systemic injection of LPS induces the expression of the interleukine-1 $\beta$ (IL-1 $\beta$ ) gene [45] and the incubation of rat pineal glands with LPS leads to the expression of the TNF and TNF receptor subtype I [43]. This effect is mediated by the nuclear translocation of p50/p50 and p50/RelA. The activation of the NFKB pathway by LPS also blocks melatonin synthesis and the later synthesis of TNF and TNFR1, which may amplify the signal [43]. A similar process could occur in humans, as a negative correlation between the increase in TNF after an acute inflammation and the level of nocturnal melatonin surge was observed [47, 48].

In summary, the pineal gland is instrumented to answer to PAMPs and pro-inflammatory cytokines through a classical pathway for signaling injury. The most evident output is the suppression of the nocturnal melatonin surge, which allows a full transmigration of immune-competent cells, independent of the hour of the day. Inasmuch, this reduction in the nocturnal melatonin surge probably plays a role in the development of sickness behavior, which in the case of infections implies in reduction of ingestive, social and sexual behaviors, the induction of lethargy and thermoregulatory changes and an alteration in the sleep/wake cycle (for a review see [49]). As a matter of fact, it is well recognized that the behavioral tolerance to endotoxin is enhanced by adaptation to winter photoperiods [3, 49].

\section{Anti-inflammatory mediators}

The inflammatory response comprises a process of activation followed by a process of deactivation in order to promote a well-tuned response that rescues the organism from aggression and restores the healthy state. In the recovery phase, anti-inflammatory mediators should play a role in restoring the nocturnal melatonin surge. Here we will describe the effect of corticosterone, which inhibits the NFKB pathway.

Corticosterone has a dual effect on noradrenalineinduced melatonin synthesis in cultured rat pineal glands [50]. Low concentration potentiates noradrenaline-induced transcription and activity of the enzyme AA-NAT and the synthesis of melatonin, while high concentration has no effect on the noradrenaline-induced NAS and melatonin synthesis $[42,50,51]$. The corticosterone effect is mediated by the activation of glucocorticoid receptors and the inhibition of the NFKB pathway [50]. The effect of low doses of noradrenaline observed in cultured pineal glands can be translated to nocturnal sympathetic stimulations, as administration of corticosterone by trans-pineal infusion has no effect on daytime melatonin output, but increases the nocturnal melatonin peak [51]. Therefore, corticosterone potentiates noradrenaline-induced melatonin synthesis either in vitro or in vivo.

Taking into account that chronic inflamed animals have a higher level of circulating corticosterone than normal animals [52], these recent results probably explain why in our initial studies, the nocturnal melatonin surge is suppressed after the adrenalectomy of mice [53]. In other words, a balance between proinflammatory mediators and corticosterone on NFKB nuclear translocation should be important for determining the nocturnal melatonin surge in chronic inflamed animals.

\section{SYNTHESIS OF MELATONIN BY IMMUNE-COMPETENT CELLS}

The shuttle between pineal and extra-pineal production of melatonin implies that activated immunecompetent cells are able to produce melatonin that is released in a paracrine manner. In 2004, two independent groups working with rat macrophages [20] and human lymphocytes [19] showed that these cells produce high concentrations of melatonin. More recently, this information was extended to other defense cells, such as human colostrum macrophages [47, 48].

The human colostrum confers protection against gastrointestinal and respiratory infection in infants [54]. The main cell lineages in this secretion ( $>80 \%$ ) consist of macrophages and neutrophils specialized in phagocytosis [55]. They are able to kill 

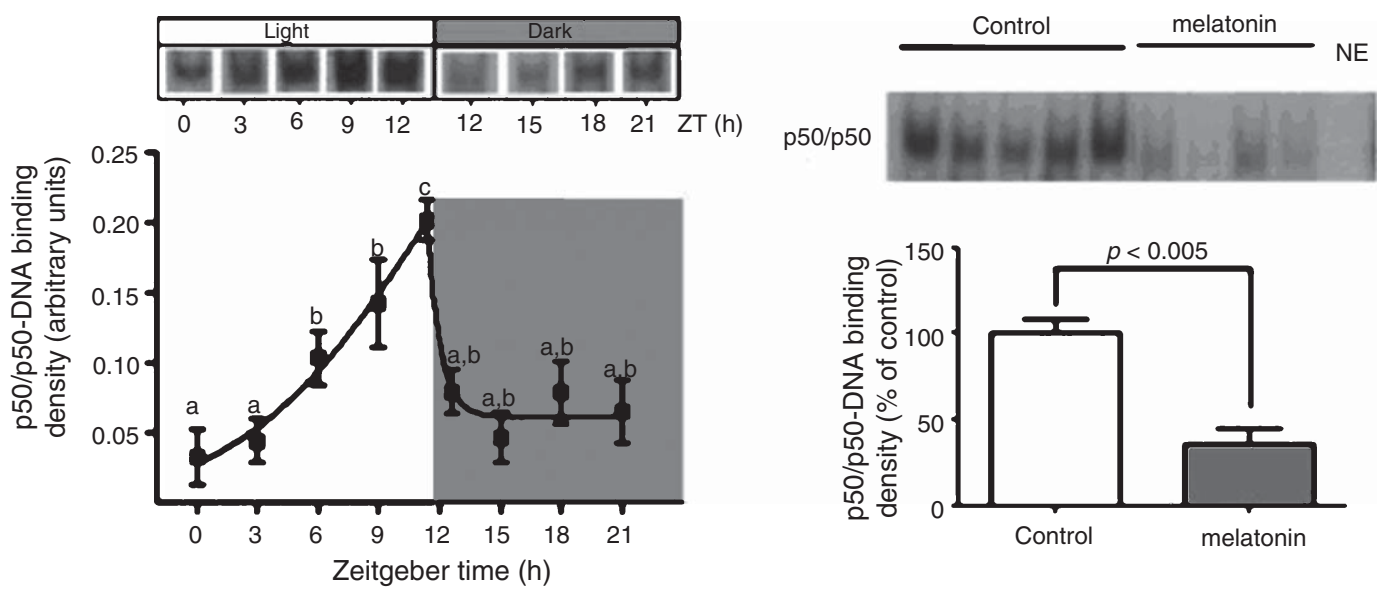

Fig. 4. NFKB transcription factor activity in pineal glands from healthy rats and non-stimulated cultures. LEFT PANEL - Daily variation of the content of NFKB in the nuclear fraction of pineal glands obtained from rats maintained under a $12 \mathrm{~h}: 12 \mathrm{~h} \mathrm{LD}$ cycle, killed at $3 \mathrm{~h}$ intervals. The gel in the superior panel is a typical eletromobility gel-shift assay (EMSA) showing the content of $p 50 / \mathrm{p} 50$ at each zeitgeber time. The lower panel shows the mean values and the standard error of the mean for 4-12 glands per timepoint. Different letters represent significant difference between the groups ( $a \neq \mathrm{b} \neq \mathrm{c} ; p<0.05$ one-way ANOVA). RIGHT PANEL - Nuclear NFKB content in cultured rat pineal glands incubated or not with melatonin $(1 \mathrm{mM}, 3 \mathrm{~h})$. EMSA shows the NFKB translocated to the nuclear extract cultured pineal glands. The densitometry confirms that melatonin inhibits NFKB nuclear translocation in pineal glands. Data are expressed as mean values and the standard errors of the mean for 4-5 glands per group. Differences among groups were tested by student t test. Abbreviation: NE= no extract. Reprinted from [53] with permission of “Informa UK Ltd.”

enteropathogenic Escherichia coli (EPEC) [56] without activating oxidative pathways, as observed with the great majority of phagocytes [57]. It is interesting to note that EPECs and zymosan induce the synthesis of high concentrations of melatonin by human macrophages [47] and enhance the ability of these cells to phagocyte EPEC and zymosan [58].

In the majority of immune-competent cells, either melatonin or one of its metabolites plays the role of an anti-inflammatory and anti-oxidant substance. This is one of the most studied effects of melatonin, and many recent excellent reviews are available [2, 5961]. These effects have the function of finishing the defense response, avoiding the generation of chronic inflammatory responses and unnecessary tissue damage.

In summary, melatonin secreted by immunecompetent cells acts as a paracrine, or even autocrine hormone, regulating the function of these cells and the defense response.

\section{THE IMMUNE-PINEAL AXIS HYPOTHESIS}

The pineal gland, classically considered the photoneuroendocrine transducer organ of mammals, is now being discovered as target for molecules that signal immune responses. In pathophsysiologi- cal conditions, mediators of inflammation modulate the synthesis of melatonin, in such a manner that pro-inflammatory mediators inhibit while anti-inflammatory mediators potentiate melatonin production.

In addition, during the course of an immune response, activated leukocytes produce melatonin, which reaches a concentration of a 100 to 1000 times higher than that found in the circulation, contributing to the improvement of bacterial phagocytosis and the recovery of the lesioned area.

Restoration of nocturnal melatonin surge is obtained not only by the reduction of pro-inflammatory signaling in the pineal gland, but also by the action of anti-inflammatory mediators. It is important to mention that the classical pathway for signaling danger (the NFKB pathway) is involved in the suppression and restoration of the nocturnal melatonin surge.

Therefore, during the mounting of an inflammatory response, the organism is disconnected from environmental cues, and the darkness hormone, melatonin, gains another function. This is a primitive function linked to organism self defense, and not self-adaptation (Fig. 1).

This new integrative view of the relationship between the pineal gland and the immune response certainly will help to explain several findings about melatonin effects regarding to pain $[62,63]$, diseases 
that involve inflammatory responses, such as stroke [64-66] or chronic inflammatory diseases [for review see 67,68$]$.

In conclusion, the pineal gland is not only a transducer of photoperiodic information, but is also a constitutive player in the innate immune response. In other words, melatonin is not only the darknesshormone, but also one of the many anti-inflammatory molecules that are produced at the sites of lesions during the recovery phase of an inflammatory response. Therefore, there is a constant crosstalk between the periphery and the pineal gland [31], which we defined as the Immune-Pineal Axis [32].

\section{REFERENCES}

[1] Tan DX, Hardeland R, Manchester LC, Paredes SD, Korkmaz A, Sainz RM, et al. The changing biological roles of melatonin during evolution: from an antioxidant to signals of darkness, sexual selection and fitness. Biol Rev Camb Philos Soc. 2010; 85(3): 607.

[2] Tomás-Zapico C, Coto-Montes A. A proposed mechanism to explain the stimulatory effect of melatonin on antioxidative enzymes. J Pineal Res. 2005; 39(2): 99.

[3] Demas GE, Nelson RJ. Seasonal changes in immune function. Q Rev Biol. 2006; 71(4): 511.

[4] Szczepanik M. Melatonin and its influence on immune system. J Physiol Pharmacol. 2007; 58(Suppl 6): 115.

[5] Baillie SR, Prendergast BJ. Photoperiodic regulation of behavioral responses to bacterial and viral mimetics: A test of the winter immunoenhancement hypothesis. J Biol Rhythms. 2008; 23(1): 81 .

[6] Nelson RJ, Demas GE. Role of melatonin in mediating seasonal energetic and immunologic adaptations. Brain Research Bulletin. 1997; 44(4): 423.

[7] Lopes C, de Lyra JL, Markus RP, Mariano M. Circadian rhythm in experimental granulomatous inflammation is modulated by melatonin. J Pineal Res. 1997; 23(2): 72.

[8] Simonneaux V, Ribelayga C. Generation of the melatonin endocrine message in mammals: a review of the complex regulation of melatonin synthesis by norepinephrine, peptides, and other pineal transmitters. Pharmacol Rev. 2003; 55(2): 325 .

[9] Mortani-Barbosa EJM, Ferriera ZS, Markus RP. Purinergic and noradrenergic cotransmission in the rat pineal gland. Eur J Pharmacol. 2000; 401(1): 59.

[10] Ferreira ZS, Markus RP. Caracterization of P2Y(1)-like receptor in cultured rat pineal glands. Eur J. Pharmacol. 2001; 415(2-3): 151.

[11] Sternberg EM, Hill JM, Chrousos GP, Kamilares T, Listwak SJ, Hilder RL. Inflammatory mediator-induced hypothalamicpytuitary-adrenal axes activation is deffective in streptoccocal cell wall arthrits-susceptible Lewis rats. Proc Natl Acad Sci USA. 1989; 86(7): 2374.

[12] Farsky SP, Sannomiya P, Garcia-Leme J. Secreted glucocorticoids regulate leukocyte-endothelial interactions in inflammation. A direct vital microscopic study. J Leukocyte Biology. 1995; 57(3): 379.

[13] Lotufo CM, Lopes C, Dubocovich ML, Farsky SH, Markus RP. Melatonin and $\mathrm{N}$-acetylserotonin inhibit leucocyte rolling and adhesion to rat microcirculation. Eur J Pharmacol. 2001; 430(2-3): 351.

[14] Pohlman TH, Stanness KA, Beatty PG, Ochs HD, Harlan JM. An endothelial cell surface factor(s) induced in vitro by lipopolysaccharide, interleukin 1 , and tumor necrosis factoralpha increases neutrophil adherence by a CDw18-dependent mechanism. J Immunol. 1986; 136(12): 4548.

[15] Lotufo CM, Yamashita CE, Farsky SH, Markus RP. Melatonin effect on endothelial cells reduces vascular permeability increase induced by leukotriene B4. Eur J Pharmacol. 2006; 534(1-3): 258.

[16] Shaikh AY, Xu J, Wu Y, He L, Hsu C. Melatonin protects bovine cerebral endothelial cells from hyperoxia-induced DNA damage and death. Neuroscience Letters. 1997; 229(3): 193.

[17] Urata Y, Honma S, Goto S, Todoroki S, Iida T, Cho S, Honma K, Kondo T. Melatonin induces $\gamma$-glutamylcysteine synthetase mediated by activator protein-1 in human vascular endothelial cells. Free Radic Biol Med. 1999; 27(7-8): 838.

[18] Tamura EK, Cecon E, Monteiro AW, Silva CL, Markus RP. Melatonin inhibits LPS-induced NO production in rat endothelial cells. J Pineal Res. 2009; 46(3): 268.

[19] Carrillo-Vico A, Calvo JR, Abreu P, Lardone PJ, GarcíaMauriño S, Reiter RJ, et al. Evidence of melatonin synthesis by human lymphocytes and its physiological significance: possible role as intracrine, autocrine, and/or paracrine substance. FASEB J. 2004; 18(3): 537.

[20] Martins E Jr., Ferreira AC, Skorupa AL, Afeche SC, CipollaNeto J, Costa Rosa LF. Tryptophan consumption and indoleamines production by peritoneal cavity macrophages. J Leukoc Biol. 2004; 75(6): 1116.

[21] Tamura EK, Fernandes PA, Marçola M, da Silveira CruzMachado S, Markus RP. Long-lasting priming of endothelial cells by plasma melatonin levels. PLoS One. 2010; 5(11): e13958.

[22] Ekström P, Meissl H. Evolution of photosensory pineal organs in new light: the fate of neuroendocrine photoreceptors. Philos Trans R Soc Lond B Biol Sci. 2003; 358(1438): 1679.

[23] Pedersen EB, Fox LM, Castro AJ, McNulty JA. Immunocytochemical and electron-microscopic characterization of macrophage/microglia cells and expression of class II major histocompatibility complex in the pineal gland of the rat. Cell Tissue Res. 1993; 272(2): 257.

[24] Moller M, Ingild A, Bock E. Immunohistochemical demonstration of S-100 protein and GFA protein in interstitial cells of rat pineal gland. Brain Res. 1978; 140(1): 1.

[25] Jiang-Shieh YF, Wu CH, Chang ML, Shieh JY, Wen CY. Regional heterogeneity in immunoreactive macrophages/ microglia in the rat pineal gland. J Pineal Res. 2003; 35(1): 45.

[26] Jiang-Shieh YF, Wu CH, Chien HF, Wei IH, Chang ML, Shieh JY, et al. Reactive changes of interstitial glia and pinealocytes in the rat pineal gland challenged with cell wall components from gram-positive and negative bacteria. J Pineal Res. 2005; 38(1): 17.

[27] Tsai S-Y, McNulty JA. Microglia in the pineal gland of the neonatal rat: characterization and effects on pinealocytes neurite length and serotonin content. Glia. 1997; 20(3): 243.

[28] Tsai S-Y, McNulty JA. Interleukin- $1 \beta$ expression in the pineal gland of the rats. J. Pineal Res. 1999; 27(1): 42.

[29] Tsai S-Y, O'Brien TE, McNulty JA. Microglia play a role in mediating the effects of cytokines on the structure and function of the rat pineal gland. Cell Tissue Res. 2001; 303(3): 433. 
[30] Withyachumnarnkul B, Nonaka KO, Attia AM, Reiter R. Changes in indole metabolism in organ cultured rat pineal glands induced by interferon-gamma. J Pineal Res. 1990; 8(4): 313 .

[31] Skwarlo-Sonta K, Majewski P, Markowska M, Oblap R, Olszanska B. Bidirectional communication between the pineal gland and the immune system. Can J Physiol Pharmacol. 2003; 81(4): 342.

[32] Markus RP, Ferreira ZS, Fernandes PACM, Cecon E. The immune-pineal axis: a shuttle between endocrine and paracrine melatonin sources. Neuroimmunomodulation. 2007; 14(3-4): 126.

[33] Belvin MP, Anderson KV. A conserved signaling pathway: the Drosophila toll-dorsal pathway. Annu Rev Cell Dev Biol. 1996; 12: 393.

[34] O'Neill LA, Greene C. Signal transduction pathways activated by the IL-1 receptor family: ancient signaling machinery in mammals, insects, and plants. J Leukoc Biol. 1998; 63(6): 650.

[35] Zhang G, Ghosh S. Toll-like receptor-mediated NF-kB activation: a phylogenetically conserved paradigm in innate immunity. J Clin Invest. 2001; 107(1): 13

[36] Smoak KA, Cidlowski JA. Mechanisms of glucocorticoid receptor signaling duringinflammation. Mech Ageing Dev. 2004; 125(10-11): 697.

[37] Kaltschmidt B, Kaltschmidt C. NF-kappaB in the nervous system. Cold Spring Harb Perspect Biol. 2009; 1(3): a001271.

[38] Marpegan L, Bekinschtein TA, Freudenthal R, Rubio MF, Ferreyra GA, Romano A, et al. Participation of transcription factors from the Rel/NF-kappa B family in the circadian system in hamsters. Neurosci Lett. 2004; 358(1): 9.

[39] Cecon E, Fernandes PACM, Pinato L, Ferreira ZS, Markus RP. 2010. Daily variation of constitutively activated nuclear factor kappa B (NFkB) in rat pineal gland. Chronobiol Int. 2010; 27(1): 52.

[40] Karin M, Yamamoto Y, Wang QM. The IKK NF-kB system: a treasure trove for drug development. Nat Rev Drug Discov. 2004; 3(1): 17.

[41] Vallabhapurapu S, Karin M. Regulation and function of NF$\mathrm{kB}$ transcription factors in the immune system. Annu Rev Immunol. 2009; 27: 693.

[42] Fernandes PA, Cecon E, Markus RP, Ferreira ZS. Effect of TNF-alpha on the melatonin synthetic pathway in the rat pineal gland: basis for a 'feedback' of the immune response on circadian timing. J Pineal Res. 2006; 41(4): 344.

[43] da Silveira Cruz-Machado S, Carvalho-Sousa CE, Tamura EK, Pinato L, Cecon E, Fernandes PA, et al. TLR4 and CD14 receptors expressed in rat pineal gland trigger NFKB pathway. J Pineal Res. 2010; 49(2): 183.

[44] Ghosh S, Hayden MS. New regulators of NF-kappaB in inflammation. Nat Rev Immunol. 2008; 8(11): 837.

[45] Wong ML, Bongiorno PB, Rettori V, McCann SM, Licinio J. Interleukin (IL) 1beta, IL-1 receptor antagonist, IL-10, and IL13 gene expression in the central nervous system and anterior pituitary during systemic inflammation: pathophysiological implications. Proc Natl Acad Sci U S A. 1997; 94(1): 227.

[47] Pontes GN, Cardoso EC, Carneiro-Sampaio MM, Markus RP. Injury switches melatonin production source from endocrine (pineal) to paracrine (phagocytes) - melatonin in human colostrum and colostrumphagocytes. J Pineal Res. 2006; 41(2): 136

[48] Pontes GN, Cardoso EC, Carneiro-Sampaio MM, Markus RP. Pineal melatonin and the innate immune response: the TNF-alpha increase after cesarean section suppress nocturnal melatonin production. J Pineal Res. 2007; 43(4): 365.
[49] Prendergas BJ. Behavioral tolerance to endotoxin is enhanced by adaptation to winter photoperiods. Psychoneuroendocrinology. 2008; 33(4): 540.

[50] Ferreira ZS, Fernandes PACM, Duma D, Assreuy J, Avellar MCW, Markus RP. Corticosterone modulates noradrenalineinduced melatonin synthesis through inhibition of nuclear factor kappaB. J Pineal Res. 2005; 38(3): 182.

[51] Fernandes PA, Bothorel B, Clesse D, Monteiro AW, Calgari C, Raison S, Simonneaux V, Markus RP. Local corticosterone infusion enhances nocturnal pineal melatonin production in vivo. J Neuroendocrinol. 2009; 21(2): 90.

[52] Nadeau S, Rivest S. Endotoxemia prevents the cerebral inflammatory wave induced by intraparenchymal lipopolysaccharide injection: role of glucocorticoids and CD14. J Immunol. 2002; 169(6): 3370.

[53] Lopes C, Mariano M, Markus RP. Interaction between the adrenal and the pineal gland in chronic experimental inflammation induced by BCG in mice. Inflammation Res. 2001; 50(1): 6 .

[54] Jason JM, Nieburg P, Marks JS. Mortality and infectious disease associated with infant-feeding practices in developing countries Pediatrics. 1984; 74(4 Pt 2): 702.

[55] Crago SS, Prince SJ, Pretlow TG, McGhee JR, Mestecky J. Human colostral cells. I. Separation and characterization. Clin Exp Immunol. 1979; 38(3): 585.

[56] Honorio-Franca AC, Carvalho MP, Isaac L, Trabulsi LR, Carneiro-Sampaio MM. Colostral mononuclear phagocytes are able to kill enteropathogenic Escherichia coli opsonized with colostral IgA Scand. J Immunol. 1997; 46(1): 59.

[57] Honorio-França AC, Launay P, Carneiro-Sampaio MM, Monteiro RC. Colostral neutrophils express Fc alpha receptors (CD89) lacking gamma chain association and mediate noninflammatory properties of secretory IgA. J Leukoc Biol. 2001; 69(2): 289.

[58] Lapa MAP, Pontes GN, Ferreira ZS, Markus RP. Molecular Characterization of NFKB signaling in human colostral mononuclear phagocytes - functional effect on peripheral melatonin synthesis. In: $40^{\circ}$. Congresso brasileiro de farmacologia e terapêutica experimental, São Paulo, Brazil; 2009.

[59] Rosales-Corral S, Reiter RJ, Tan DX, Ortiz GG, LopezArmas G. Functional aspects of redox control during neuroinflammation. Antioxid Redox Signal. 2010; 13(2): 193.

[60] Korkmaz A, Topal T, Tan DX, Reiter RJ. Role of melatonin in metabolic regulation. Rev Endocr Metab Disord. 2009; 10(4): 261.

[61] Konturek SJ, Konturek PC, Brzozowski T. Melatonin in gastroprotection against stress-induced acute gastric lesions and in healing of chronic gastric ulcers. J Physiol Pharmacol. 2006; 57(Suppl 5): 51.

[62] Caumo W, Torres F, Moreira NL Jr, Auzani JA, Monteiro CA, Londero G, Ribeiro DF, Hidalgo MP. The clinical impact of preoperative melatonin on postoperative outcomes in patients undergoing abdominal hysterectomy. Anesth Analg. 2007; 105(5): 1263-1271.

[63] Caumo W, Levandovski R, Hidalgo MP. Preoperative anxiolytic effect of melatonin and clonidine on postoperative pain and morphine consumption in patients undergoing abdominal hysterectomy: a double-blind, randomized, placebo-controlled study. J Pain. 2009; 10(1): 100-108

[64] Dominguez-Rodriguez A, Abreu-Gonzalez P, GarciaGonzalez MJ, Kaski JC, Reiter RJ, Jimenez-Sosa A. A unicenter, randomized, double-blind, parallel-group, placebocontrolled study of Melatonin as an Adjunct in patients with acute myocardial Infarction undergoing primary Angioplasty 
- The Melatonin Adjunct in the acute myocaRdial Infarction treated with Angioplasty (MARIA) trial: study design and rationale. Contemp Clin Trials. 2007; 28(4): 532-539.

[65] Cheung RT, Tipoe GL, Tam S, Ma ES, Zou LY, Chan PS Preclinical evaluation of pharmacokinetics and safety of melatonin in propylene glycol for intravenous administration. J Pineal Res. 2006; 41(4): 337-343.

[66] Pei Z, Pang SF, Cheung RT. Pretreatment with melatonin reduces volume of cerebral infarction in a rat middle cere- bral artery occlusion stroke model. J Pineal Res. 2002; 32(3): 168-172.

[67] Maestroni GJ, Cardinali DP, Esquifino AI, Pandi-Perumal SR. Does melatonin play a disease-promoting role in rheumatoid arthritis? J Neuroimmunol. 2005; 158(1-2): 106-11.

[68] Srinivasan V, Spence DW, Trakht I, Pandi-Perumal SR, Cardinali DP, Maestroni GJ. Immunomodulation by melatonin: its significance for seasonally occurring diseases. Neuroimmunomodulation. 2008; 15(2): 93-101. 